www.jmscr.igmpublication.org

Index Copernicus Value: 79.54

ISSN (e)-2347-176x ISSN (p) 2455-0450

crossrefDOI: https://dx.doi.org/10.18535/jmscr/v7i2.170

\title{
Traumatic Posterior Fossa Extradural Hematoma-Experience at a Tertiary Care Centre
}

Authors

\author{
Vidhya Narasimhan $^{1 *}$, K Deiveegan ${ }^{2}$, R Mohan Kumar ${ }^{3}$ \\ ${ }^{1}$ Kilpauk Medical College, Chennai, India \\ ${ }^{2}$ SRM Medical College, Chennai, India \\ ${ }^{3}$ Directorate of Public Health and Preventive Medicine, Chennai, India \\ Department of Neurosurgery, Madras Medical College, Chennai, India \\ *Corresponding Author \\ Vidhya Narasimhan
}

Mailing address: F3, Kanakadhara Tiruvengadam, 7/3, cart track road, T Nagar, Chennai, India, 600017

Email: drvidhya.n@gmail.com, Phone: 9444069453

\begin{abstract}
Traumatic Posterior Fossa Extradural Hematoma (PFEDH) needs immediate and appropriate management because, the proximity to brain stem and the smaller posterior fossa volume can lead to rapid deterioration of the patient. This study was done to analyse the demographic profile, mode of injury, clinical features and management of PFEDH and the factors associated with outcome. 8512 patients admitted with head injury in 3 year period were studied prospectively. Of the 8512 patients, 702 (8.2\%) had EDH. 45 patients (6.4\% of EDH) had PFEDH. The Common presenting history were post traumatic loss of consciousness and vomiting. Occipital fracture was found in $82 \%$ and Supratentorial extension of PFEDH was found in $18 \%$ of cases. $60 \%$ of patients underwent surgical evacuation of PFEDH. 89\% (40) patients had good outcome (GOS-5) and mortality rate was $8.8 \%$ (4). $98 \%$ of patients with GCS > 8 had good outcome compared to $25 \%$ in patients with GCS $<=8$. Out of 4 patients who expired, 3(75\%) had other associated severe intradural injuries. Road Traffic Accident (RTA) was the commonest mode of injury in adults and fall in children. RTA and train accidents were often associated with countercoup intradural hematomas. Volume of PFEDH was an important factor in deciding the line of management. Admission GCS score was the most important predictor of outcome. Children and elderly had good outcome. Associated intradural hematomas led to poorer outcome.
\end{abstract}

Keywords: Extradural hematoma, head injury.

\section{Introduction}

Posterior fossa is unique because it contains the brain stem and is smaller in volume than the supratentorial compartment of the cranium. In the acute scenario of traumatic brain injury, when there is extradural hematoma in the posterior 
fossa, there is a risk of early brain stem herniation leading to rapid fall in conscious level and irreversible brain stem dysfunction. Hence, though relatively infrequent in occurrence, early identification and immediate appropriate management of Posterior Fossa Extradural Hematoma (PFEDH) is essential for successful neurotrauma management. In this study the demographic profile, clinical status at admission, management, outcome and prognostic factors of PFEDH are studied prospectively in patients admitted over a period of 3 years.

\section{Objectives}

- To study the incidence, demographic profile, mode of injury, presenting features and management of PFEDH.

- To analyse factors associated with the outcome of the patients.

\section{Methods}

Patients with head injury treated at the department of neurosurgery, Madras Medical College and Rajeev Gandhi Government General hospital, Chennai for a period of three years were studied. Clinical assessment at admission was done using Glasgow coma scale (GCS) and age adjusted GCS scale for children. Management of the patients was based on institutional guidelines and was individualised for each patient by the treating neurosurgeon. This is a prospective cross sectional study and the study did not influence the line of management.

Conservative management was done to patients admitted with one or more of the following

$>$ GCS 13 to 15

$>$ Radiological PFEDH volume $<15 \mathrm{cc}$

$>$ No mass effect over $4^{\text {th }}$ ventricle or no hydrocephalus

$>$ No clinical signs or symptoms of ICP

Surgical management was done to patients admitted with one or more of the following

$>$ Volume of PFEDH $>=15 \mathrm{cc}$

$>$ Compression of fourth ventricle with or without hydrocephalus

\section{Low GCS (GCS 12or below)}

The outcome was assessed by the Glasgow outcome scale (GOS) at discharge

\section{Inclusion criteria}

All patients admitted in trauma ward in Madras medical college and treated for head injury in the department of neurosurgery from January 2011 to December 2013 were included. Of these, patients with PFEDH were recruited in the study.

\section{Exclusion criteria}

1) Patients with polytrauma where nonneurosurgical trauma needed priority of management or surgery

2) Non-traumatic PFEDH

Data collection: Data was collected through a pre-designed questionnaire by the PI. The clinical information was extracted from the case sheet using a data extraction form

Data analysis: Data entry was done in excel and data analysis was done in Epi info7. Proportion and odds ratio with $95 \%$ confidence interval were calculated. Dose response odds ratio was calculated using open epi software

\section{Results}

Of the 8512 patients admitted with head injury from Jan 2011 to Dec 2013, 702 (8.2\%) patients had EDH. $45(0.53 \%)$ of the head injury patients (6.4\% of EDH patients) had PFEDH. 40 (89\%) of the 45 patients with PFEDH had good outcome with GOS 5. One (2\%) recovered with GOS 3. Mortality rate was $8.8 \%$. (Fig 1)

Fig 1: Overview of cases of Posterior Fossa Extra Dural Hematoma in a Tertiary care centre

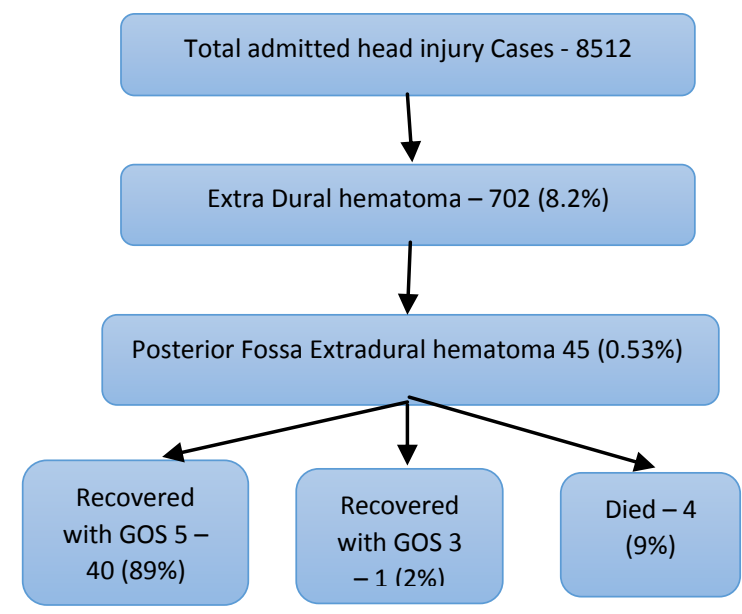


PFEDH was seen more in people in the age group of 13 to 60 years $(31,69 \%)$, followed by the age group 1 to 12 years $(9,20 \%)$. Majority of them were males $(39,87 \%)$

Road traffic accident (RTA) $(22,48 \%)$ was the commonest mode of injury followed by fall (18, $40 \%$ ). RTA was the most common mode of injury in adults, fall in children and elderly. The Common presenting history were post traumatic loss of consciousness $(30,83 \%)$ followed by vomiting. $6(13.6 \%)$ patients had GCS less than 8 , $2(7.4 \%)$ of them had signs of brainstem dysfunction. Radiological or intra operative fracture was found in $37(82 \%)$ patients. Intra cranial air pockets were found in 10 (22\%) patients. Presence or absence of Fracture was found to have no impact on the size of the hematoma.

All three patients brought within one-hour post trauma, had admission GCS > 10 and had good outcome (GOS 5), signifying the importance of very early intervention before deterioration.
All 16 patients with volume of PFEDH $<15 \mathrm{cc}$ were managed conservatively and had good outcome (Table 1). With increasing volume the presence of mass effect was found to increase. All 27 who underwent surgery had PFEDH volume more than or equal to $15 \mathrm{cc}$, whereas only $7(26 \%)$ of them had GCS 12 or below at admission. With prompt surgical management of PFEDH, out of 7 patients with volume> 30cc, 6(86\%) had good outcome (GOS 5). Extension of Extradural hematoma into supratentorial compartment was found in $8(18 \%)$ cases and $6(75 \%)$ of them were operated.

Table 1: Higher PFEDH volume as an indication for surgery and as a predictor of outcome in a tertiary care centre

\begin{tabular}{|c|c|c|c|c|c|c|c|c|c|}
\hline \multirow{2}{*}{$\begin{array}{l}\text { Vol of } \\
\text { PFEDH } \\
\text { in CC }\end{array}$} & \multirow{2}{*}{$\begin{array}{c}\# \\
\text { cases }\end{array}$} & \multirow{2}{*}{$\begin{array}{l}\text { Mass } \\
\text { effect }\end{array}$} & \multirow{2}{*}{$\begin{array}{c}\text { Surgery } \\
\text { done }\end{array}$} & \multicolumn{3}{|c|}{ GCS } & \multicolumn{3}{|c|}{ GOS } \\
\hline & & & & $\begin{array}{l}13- \\
15\end{array}$ & $\begin{array}{l}9- \\
12\end{array}$ & $<=8$ & 5 & 3 & 1 \\
\hline$<15$ & 16 & 0 & 0 & 14 & 2 & 0 & 16 & 0 & 0 \\
\hline $15-29$ & 22 & 8 & 21 & 17 & 2 & 3 & 18 & 1 & 3 \\
\hline$>=30$ & 7 & 7 & 7 & 5 & 1 & 1 & 6 & 0 & 1 \\
\hline
\end{tabular}

Table 2: Factors associated with outcome of patients admitted with posterior fossa extra Dural hematoma in a tertiary care hospital

\begin{tabular}{|c|c|c|c|c|c|c|}
\hline Characteristics & Description & GOS $=5$ & GOS $<5$ & Odds ratio & $95 \% \mathrm{CI}$ & P Value \\
\hline \multirow{2}{*}{ Age } & Up to 12 years & 11 & 0 & \multirow{2}{*}{-} & \multirow{2}{*}{0.39 - undefined } & \multirow{2}{*}{0.22} \\
\hline & $>12 \mathrm{yrs}$ & 29 & 5 & & & \\
\hline \multirow{2}{*}{$\begin{array}{l}\text { Admission within } \\
\text { hours }\end{array}$} & Up to 4 hours & 14 & 2 & \multirow{2}{*}{0} & \multirow{2}{*}{$0.0-5.03$} & \multirow{2}{*}{0.342} \\
\hline & $>4$ hours & 11 & 0 & & & \\
\hline \multirow{2}{*}{ EDH Volume } & Up to $15 \mathrm{cc}$ & 25 & 1 & \multirow{2}{*}{6.392} & \multirow{2}{*}{$0.73-170.9$} & \multirow{2}{*}{0.101} \\
\hline & $>15 \mathrm{cc}$ & 15 & 4 & & & \\
\hline \multirow{2}{*}{ Craniectomy } & Yes & 23 & 4 & \multirow{2}{*}{0.35} & \multirow{2}{*}{$0.01-3.04$} & \multirow{2}{*}{0.39} \\
\hline & No & 17 & 1 & & & \\
\hline \multirow{2}{*}{ GCS } & $>8$ & 40 & 1 & \multirow{2}{*}{-} & \multirow{2}{*}{$\begin{array}{c}13.52- \\
\text { undefined }\end{array}$} & \multirow{2}{*}{0.0000} \\
\hline & Up to 8 & 0 & 4 & & & \\
\hline \multirow{2}{*}{ ST Extension } & Yes & 12 & 4 & \multirow{2}{*}{0} & \multirow{2}{*}{$0-0.89$} & \multirow{2}{*}{0.039} \\
\hline & No & 18 & 0 & & & \\
\hline \multirow{2}{*}{ Mass effect } & Yes & 12 & 4 & \multirow[b]{2}{*}{0} & \multirow{2}{*}{$0.0-0.72$} & \multirow{2}{*}{0.02} \\
\hline & No & 22 & 0 & & & \\
\hline
\end{tabular}

$27(60 \%)$ patients underwent craniectomy and evacuation of EDH and 18 were managed conservatively. Surgical management was required in $73 \%$ of children, $58 \%$ of young adults and $33 \%$ of elderly. Out of the 27 cases operated, 7 (26\%) patients were found to have transverse sinus injury, which was controlled during surgery. Associated other intra cranial injuries like contusions brain, subdural hematoma were found in 19(42\%) patients. Around half (53\%) of these patients had counter coup unilateral or bilateral frontal contusion brain. 3 patients with supratentorial hematomas required supratentorial craniotomy also. Out of 4 patients who expired, 3 (75\%) had associated severe intradural injuries (fig 2) (2 supratentorial intracerebral hematomas, 1 brain stem contusion). 
Fig 2: Factors influencing the outcome of Posterior Fossa Extra Dural Hematoma in a Tertiary care centre

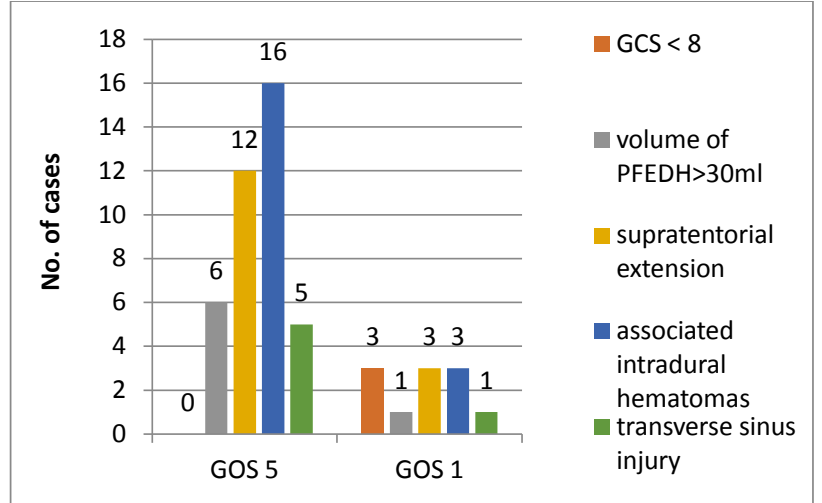

Children and elderly had 100\% good outcome (GOS 5). Patients admitted with GCS more than 8 are strongly associated with having GOS 5 at discharge, compared to patients with GCS 8 or lesser ( $p$ value - 0.0000) (Table 2). The dose response analysis of GCS during admission shows that lower the GCS during admission, lesser the GOS at discharge ( $p$ value -0.0000) (Table 3$)$.

Table 3: Glasco-coma scale as a factor associated with outcome of patients admitted with posterior fossa extra Dural hematoma in a tertiary care hospital

\begin{tabular}{lccccc}
\hline $\begin{array}{c}\text { Charact } \\
\text { eristics }\end{array}$ & $\begin{array}{c}\text { Descripti } \\
\text { on }\end{array}$ & GOS=5 & $\begin{array}{c}\text { GOS } \\
\mathbf{< 5}\end{array}$ & $\begin{array}{c}\text { Odds } \\
\text { Ratio }\end{array}$ & $\begin{array}{c}\text { P } \\
\text { value }\end{array}$ \\
\hline \multirow{4}{*}{ GCS } & $\begin{array}{c}\text { Baseline } \\
(14-15)\end{array}$ & 29 & 1 & 1 & \\
\cline { 2 - 5 } & $\begin{array}{c}\text { I strata }(9 \\
-13)\end{array}$ & 10 & 0 & Undefined & \multirow{2}{*}{0.0000} \\
\cline { 2 - 4 } & $\begin{array}{c}\text { II strata } \\
(5-8)\end{array}$ & 0 & 1 & 0 & \\
\cline { 2 - 4 } & $\begin{array}{c}\text { III strata } \\
\text { (Up to 4) }\end{array}$ & 0 & 3 & 0 & \\
\hline & & & & & 0
\end{tabular}

\section{Discussion}

Posterior cranial fossa lodges the most vital structure of brain, the brain stem. It is smaller in volume than the supratentorial compartment. Injury to occipital region can cause occipital fracture and PFEDH. When the PFEDH is large or enlarging in size it can cause rapid fall in conscious level and brain stem dysfunction. Therefore the importance of early identification and management of these injuries cannot be overemphasised.

Bozbuga et $\mathrm{al}^{(1)}$ have studied 73 cases of PFEDH and found its incidence to be $10 \%$ of EDH cases.
In their study $81 \%$ of patients underwent surgical treatment and mortality rate was $5.4 \%$. Malik et $\mathrm{al}^{(2)}$ studied 61 patients of PFEDH admitted in a period of 10 years retrospectively and concluded that good GCS score at admission and paediatric age group had better outcome. Verma et $\mathrm{al}^{(3)}$ have reported $88 \%$ good outcome similar to the present study. Mortality rate in our study is $8.8 \%$ which is comparable to $11.1 \%$ reported by $\operatorname{Asanin}_{(4)}$

Though PFEDH forms a small subgroup of EDH patients accounting for 6 to $10 \%$, it needs more urgent management, before irreversible brainstem herniation occurs. This requires vigilant paramedical and medical care right from the site of accident, early shifting to neurosurgical care, high index of suspicion in cases of occipital trauma and prompt management.

Among all the clinico-radiological parameters, volume of PFEDH is the most important factor in deciding the line of management, as also suggested by Prasad et $\mathrm{al}^{(5)}$. In this study though all the patients who required surgery had volume of PFEDH more than $15 \mathrm{cc}$, only $25 \%$ of them had GCS below 13. This is in line with the observation of Bozbuga et $\mathrm{al}^{(1)}$ that patients with PFEDH should be operated based on radiological indications without waiting for clinical deterioration, in order to get a good outcome. Corollary to this, majority of patients even with PFEDH volume as high as $30 \mathrm{cc}$ or even more have good outcome, with prompt surgical evacuation. This reiterates the value of prompt surgical evacuation of the hematoma as suggested by Gupta et $\mathrm{al}^{(6)}$ and Ersahin et $\mathrm{al}^{(7)}$ and reveals that higher volume of PFEDH per se does not have negative impact on outcome.

Children with PFEDH require surgery more often than adults due to the smaller posterior fossa volume and elderly require surgery less often, as atrophic brain can accommodate more volume. Children have very good outcome, as also stated by Nayil et $\mathrm{al}^{(8)}$ and Malik et $\mathrm{al}^{(2)}$. This can be attributed to the plasticity and better adaptive recovery of children's brain. 
Admission GCS score is the single most important predictor of outcome, with GCS more than 8 having strong association with good outcome (GOS 5). GCS at admission is directly proportional to GOS at discharge, better the GCS better the outcome. This is consistent with that reported by Balik et $\mathrm{al}^{(9)}$, Jang et $\mathrm{al}^{(10)}$ and Prusty et $\mathrm{al}^{(11)}$. Lower GCS indicates loss of brain function which may not be reversed with evacuation of hematoma, hence poorer outcome. Patients with low GCS at admission can be divided into two subsets, one with primary severe irreversible head injury at impact itself and the other with progressive fall in GCS with time, due to enlarging PFEDH, causing secondary brain damage. The second set of patients would have good outcome if intervened before or soon after deterioration. This again reinforces the importance of early intervention of PFEDH compared to other types of head injuries.

In high velocity accidents countercoup injury in form of brain contusion and subdural hematoma are often found. Bifrontal contusion brain is the most common countercoup injury in PFEDH in this study. Intradural countercoup injuries requiring surgery in addition that for PFEDH, are associated with poorer outcome, thus making presence of severe countercoup injury, an independent determinant of poorer outcome. Associated intradural injuries and its severity, was found to be an important determinant of outcome by Balik et $\mathrm{al}^{(9)}$, Jang et $\mathrm{al}^{(10)}$ and Prusty et $\mathrm{al}^{(11)}$.

\section{Conclusion}

- Conscious level at admission and associated severe intradural injuries are important determinants of outcome.

- Children require surgical management more often but have better outcome than adults.

- Early intervention gives good outcome even in large PFEDH.

- Volume of EDH is the most important factor in deciding the line of management.

\section{References}

1. Bozbuğa, M., İzgi, N., Polat, G., \& Gürel, I. (1999). Posterior fossa epidural hematomas: observations on a series of 73 cases. Neurosurgical review, 22(1), 34-40.

2. Malik, N. K., Makhdoomi, R., Indira, B., Shankar, S., \& Sastry, K. (2007). Posterior fossa extradural hematoma: our experience and review of the literature. Surgical neurology, 68(2), 155-158. doi:10.1016/j.surneu.2006.10.051

3. Verma, S. K., Borkar, S. A., Singh, P. K., Tandon, V., Gurjar, H. K., Sinha, S., ... \& Sharma, B. S. (2018). Traumatic posterior fossa extradural hematoma: Experience at level I trauma center. Asian journal of neurosurgery, 13(2),

227. doi:10.4103/1793-5482.228536

4. Ašanin, B. (2009). Traumatic epidural hematomas in posterior cranial fossa. Acta clinica Croatica, 48(1), 27-30.

5. Prasad, G. L., Gupta, D. K., Sharma, B. S., \& Mahapatra, A. K. (2015). Traumatic pediatric posterior fossa extradural hematomas: a tertiary-care trauma center experience from India. Pediatric neurosurgery, 50(5), 250-256, doi:10.1159/000438488

6. Malik, Nayil Khursheed, et al. "Posterior fossa extradural hematoma: our experience and review of the literature." Surgical neurology $68.2 \quad$ (2007): 155-158, doi:10.1016/j.surneu.2006.10.051

7. Gupta, P. K., Mahapatra, A. K., \& Lad, S. D. (2002). Posterior fossa extradural hematoma. The Indian Journal of Pediatrics, 69(6), 489-494.

8. Ersahin, Y., \& Mutluer, S. (1993). Posterior fossa extradural hematomas in children. Pediatric neurosurgery, 19(1), 31-33, doi:10.1159/000120697

9. Balik, V., Lehto, H., Hoza, D., Sulla, I., \& Hernesniemi, J. (2010). Posterior fossa extradural haematomas. Central European Neurosurgery-Zentralblatt 
Neurochirurgie, 71(04), 167-172, doi:10.1055/s-0030-1249046

10. Jang, J. W., Lee, J. K., Seo, B. R., \& Kim, S. H. (2011). Traumatic epidural haematoma of the posterior cranial fossa. British journal of neurosurgery, 25(1), 5561, doi:10.3109/02688697.2010.520759

11. Prusty, G. K., \& Mohanty, A. (1995). Posterior fossa extradural haematoma. Journal of the Indian Medical Association, 93(7), 255-8. 